\title{
Detection of Foot-and-Mouth Disease Sub-clinical infection in sheep imported from free zones of Georgia during Hajj season 2009 in Kingdom of Saudi Arabia
}

\author{
S. M. Ali ${ }^{* 1,3}$, M. R. Yousef ${ }^{1,3}$, S. S. A. Sharawi $i^{2,3}$ and M.H.Al-Blowi ${ }^{3}$ \\ 1. Department of FMD, Veterinary Serum and Vaccine Research Institute, Abbasia, Cairo, 11381, \\ Egypt. 2. Department of Virology, Faculty of Veterinary Medicine, Banha University, 13736 \\ Moshtoher, Egypt. 3. Central Veterinary Diagnostic Lab, Ministry of Agriculture, Riyadh, 11195, \\ Kingdom of Saudi Arabia. \\ *Corresponding author email: samir.ali9@gmail.com; samir.ali9974@yahoo.com \\ Received: 05-03-2011, Accepted: 29-03-2011, Published Online: 16-07-2011 \\ doi: $10.5455 /$ vetworld.2011.399-403
}

\begin{abstract}
Foot and mouth disease (FMD) sub-clinically infected animals, are always a threat to susceptible herds. During Hajj season 2009 (1431 Hijri) the kingdom of Saudi Arabia (KSA) imported about 204,583 sheep from FMD free areas from Republic of Georgia through Jeddah Islamic seaport. The animals were clinically free from FMD and authorized as not been previously vaccinated. However, but during the routine laboratory examination of serum samples using FMD-3ABC ELISA some sheep consignments exhibited positivness for FMD anti-bodies. The liquid phase blocking ELISA (LPBE) was performed as a confirmatory test which revealed antibodies against FMD serotype $\mathrm{O}$, the suggesting that animals may be susceptible to FMD infection from any endemic countries passed through during overseas transportation. This study will contribute towards the development of an appropriate strategy for FMD control, including the choice of countries of the animal importation, as well as assist to improve our understanding of the epidemiology of FMD.

Keywords: Foot and Mouth Disease virus, Enzyme linked Immunosorbent Assay, Liquid phase, Blocking ELISA, Non-Structural Protein.
\end{abstract}

\section{I ntroduction}

Foot-and-mouth disease virus (FMDV) is a member of the Picornaviridae family belongs to the genus Aphthovirus that causes a highly contagious vesicular disease of cattle and other cloven- hoofed animals (Bachrach, 1968 and Pereira, 1981). Although mortality due to the foot-and-mouth disease (FMD) is very low and mostly restricted to young animals, drastic decrease in productivity and working capacity of the animals causes great losses to the livestock industry. One of the mechanisms of FMDV spread is the carriage of droplets and droplets nuclei exhaled in the breath of infected animals, such spread can be rapid and extensive, and is known in certain circumstances to have transmitted disease over a distance of several hundred kilometers (Mikkelsen,T. et al., 2003).

Sheep and goats are highly susceptible to infection with FMDV by the aerosol route; the virus probably most often infects sheep and goats by direct contact (Kitching and Hughes 2002).

The disease has an important socio-economic impact in countries where it is endemic (Astudillo et al., 1990 and Perry et al ., 1999). FMD provokes huge economic consequences when outbreaks occur in disease free regions, and considered one of the most important barriers to world trade of livestock and animal products (Melo et al., 2002 and Huang et al., 2000).

An annual report on the global situation for FMD was provided by the World Reference Laboratory for FMD at Pirbright, UK in 2006 and revealed that; FMD is present in many areas of the world, with the exception of countries in north and central America (North of panama), Australia, NewZealand,Chile and European union (EU) (OIE, 2006).

FMD was last reported to the OIE in the southern Caucasus region, covering Georgia, Armenia and Azerbaijan, in 2002 (OIE, 2006). While serotypes A and $\mathrm{O}$ had frequently been found in Armenia and Georgia, outbreaks of serotype Asia-1 have occurred in the region in 2000/2001. Due to the passive disease reporting systems, the true occurrence of FMD 
Detection of FMD Sub-clinical infection in sheep imported from free zones of Georgia during Hajj season 2009

Table-1 Details of different sheep consignments imported from Republic of Georgia.

\begin{tabular}{cccc}
\hline $\begin{array}{l}\text { Number of animal } \\
\text { consignments }\end{array}$ & Date of consignments & $\begin{array}{c}\text { Number of sheep } \\
\text { per consignment }\end{array}$ & $\begin{array}{c}\text { Number of samples for } \\
\text { FMD examination }\end{array}$ \\
\hline 1 & $25 / 10 / 2009$ & 1284 & 200 \\
2 & $30 / 10 / 2009$ & 14071 & 140 \\
3 & $12 / 11 / 2009$ & 8071 & 100 \\
4 & $16 / 11 / 2009$ & 8499 & 100 \\
5 & $19 / 11 / 2009$ & 39892 & 100 \\
6 & $21 / 11 / 2009$ & 14413 & 100 \\
7 & $24 / 11 / 2009$ & 6500 & 100 \\
8 & $27 / 11 / 2009$ & 55500 & 100 \\
10 & $29 / 11 / 2009$ & 36263 & 100 \\
11 & $20 / 1 / 2009$ & 4250 & 50 \\
\end{tabular}

remains unclear. In the neighboring countries of Iran and Turkey serotypes A, O are endemic (FAO, 2006; OIE, 2006 and Gilbert, et.al., 2005).

An FMD vaccination buffer zone has been maintained in Armenia, Azerbaijan and Georgia with the support of the FAO. The buffer zone covers districts of the three countries bordering Iran and Turkey, and is between 10 and $60 \mathrm{~km}$ wide. Buffer zone vaccination using trivalent $\mathrm{A} / \mathrm{O} / \mathrm{Asia}-1$ vaccine has regularly been carried out since spring 2004 (FAO, 2006 and OIE 2006). Before 2004, vaccinations were often irregular. Besides the buffer zone vaccination additional national campaigns, also using nonpurified vaccines, have been carried out according to the resources available and the risks perceived. The risk of FMD introduction and spread is largely influenced by extensive regional movements to and from summer pastures, and between production areas, markets and slaughter locations, as well as cross border movements of animals. None of the countries internationally trades FMD susceptible livestock on a larger commercial scale (Potzch, et al., 2006).

The FMD virus genome encodes a unique poly protype from which the different viral polypeptides are cleaved by viral proteases, including eight different non-structural proteins (NSPs). Both structural and non-structural antigens induce the production of antibodies in infected animals. An immunoenzymatic assay (liquid phase blocking ELISA) can detect antibodies against FMDV structural protein in sheep, indicating that unrecognized FMD-infected sheep could represent a potential risk of FMD dissemination (Blanco et al., 2002).

In contrast, vaccinated animals which have not been exposed to replicating virus will develop antibodies only to the viral antigens in the inactivated material (Clavijo,et.al., 2004). The detection of antibodies to non-structural protein (NSP) of FMDV has been used to identify past or present infection (DeDiego ,et al., 1997; Brocchi ,et al., 1998; Dekker, et.al., 1998 and Malirat, et al., 1998).

In recent years, the potential value of the nonstructural proteins (NSP) 2C and 3ABC has been well documented for differentiation of infected from vaccinated animals with FMDV (DIVA) (Lu, et.al., 2010). Perhaps the most reliable single NSP indicator is the polyprotein $3 \mathrm{ABC}$ antibodies which appears to provide conclusive evidence of previous infection (Mackay,et.al., 1998). The antibodies against 3ABC have been detected up to 395 days post infection in both cattle and sheep (Sorensen,et.al., 1997).

The present study aims to explain the rapid detection and sero-typing of FMD virus in sheep that came from free zones in Georgia using the $3 \mathrm{ABC}$ FMD ELISA and LPBE as a preliminary line of preventing the entrance and spread of the FMD in to Saudi Arabia.

\section{Materials and Methods}

1. Serum samples: A total of 1140 sheep serum samples were examined for FMD from different consignment of animals that came from Georgia according to the animal quarantine laws of Jeddah Islamic seaport animal quarantine (Table1).

2. Foot-and-mouth disease antibody test kit (FMD-3ABC bo-ov): FMD-3ABC bo-ov was provided by IDEXX Laboratories, Netherlands and manufactured by IDEXX Lieberfeld-bern Switzerland. The test detects antibodies against non- structural proteins of FMD and was performed as described by the manufacturer's guide and according to the following calculation formula:

Value \% = O.D samples - O.D negative $/$ O.D positive - O.D negative $\mathrm{x} 100$

O.D: optical density

Above 30\% +ve, Less than $20 \%$ - ve, 20\% - 30\% ambiguous. 
Table-2. Detection of FMD-3ABC antibodies in different sheep consignment.

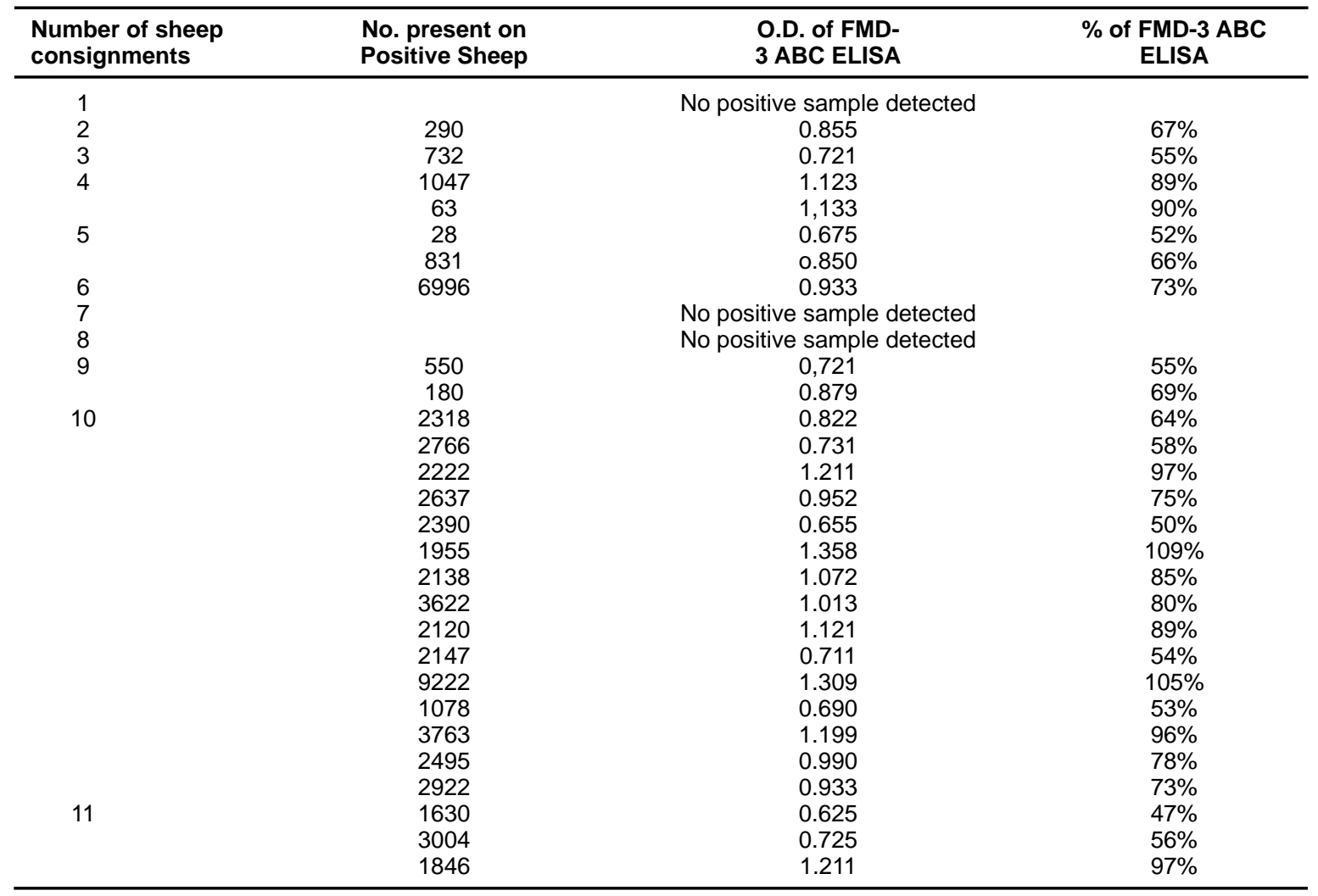

Negative: negative control $(\mathrm{O} . \mathrm{D}=0.064=0 \%)$

Positive; positive control (O.D $=1.242=100 \%$ )

3. Liquid phase blocking ELISA (LPBE): LPBE technique for the detection of FMDV antibodies in serum was described by ( Hamblin,et.al., 1986 a, b). The test is based upon specific blocking of the FMDV antigen in liquid phase by antibodies in the test serum. Rabbit antisera specific for the different serotypes of FMDV are passively adsorbed to polystyrene micro wells. After the test serum is allowed to react with the specific FMDV antigen, the test serum/antigen mixture is then transferred to an ELISA plate coated with FMDV trapping antibodies (guinea pig antisera to the 7 FMDV serotypes). The presence of antibodies to FMDV in the serum sample will result in the formation of immune complexes and consequently reduce the amount of free antigen trapped by the immobilized rabbit antisera. In turn, fewer guinea pig anti-FMDV detecting antibodies will react in the next incubation step. After the addition of enzyme-labeled (horse radish peroxidase, HRP) anti-guinea pig Ig conjugate and substrate/chromogen solution, a reduction in color development will be observed when compared to controls containing free antigen only.

\section{Results}

The results in table 2 showed that some of the collected sera from consignment numbers 2,3,4,5,6,9, 10,11 revealed positivness for specific antibodies against non- structural protein $3 \mathrm{ABC}$ by using FMD$3 \mathrm{ABC}$ ELISA, percentage positive ranging from $35 \%$ to $109 \%$. The LPBE serotyped all NSP positive sera FMD serotype $\mathrm{O}$.

\section{Discussion}

There are severe international trade restrictions on FMD affected areas, so KSA government decided to import the animals for adahhi (2009) from free areas as Republic of Georgia. In animal quarantine of Jeddah Islamic seaport, one of the important strategies for control and eradication of FMD is to detect and prevent the entrance of infected or carrier animal to KSA.The identification of animals which are currently or previously infected with FMD is very important, taking into consideration that, apparently healthy animal may be the source of a new outbreak. 
The only way to efficiently identify infected or carrier sheep serologically is by the detection of antibodies against non-structural proteins of FMDV, as NSP antibodies only develop initially following infection of animals with FMDV and not post vaccination with purified inactivated vaccine. The NSP test is a single test can be used to detect antibodies to any of the seven serotypes of FMD and consider a major advance in the epidemiological tools for FMDV diagnosis (Bronsvoort, et.al,. 2004).

The current study illustrated that the detection of FMDV $3 \mathrm{ABC}$ antibodies in certain consignments, while other consignments were negative for $3 \mathrm{ABC}$ ELISA implies that these animals originate from FMD free areas, although no clear clinical symptoms of FMD were noticed,. According to the manufacturer and (Bronsvoort, et.al., 2004), the test is very specific to detect the FMD infection and this agreed with (Bruderer, et.al., 2004) who found that 3ABC showed a specificity $>99 \%$ for bovine, ovine and porcine sera infected with FMD.

The virology laboratory of veterinary quarantine discovered that the presence of FMD-3ABC antibodies in some animals samples imported from Georgia, although these animals came with a veterinary health certificate. The last outbreak in Georgia was caused by serotype A (A/Iran/99) in 1999 (Rayan, 2000) while the current consignment of sheep tested positive for serotype $\mathrm{O}$ by the LPBE. The current results may be attributed to the exposure of the animals to FMD infection during the overseas transportation from the endemic countries passed through due to airborne effect of FMD. This agreed with (Gloster, et. al., 2007) who stated that the FMD is airborne viral disease and can be transmitted up to many kilometers from a virus source such spread may reach over a distance of several hundred kilometers (Mikkelsen, et al.,2003). But another speculation is that, the animal came from Georgia infected with serotype $\mathrm{O}$, although the infection occurred during the overseas transportation seems like a more plausible explanation as FMD has not been reported in Georgia since 2002 (OIE, 2006).

\section{Conclusion}

In summary, the current study supports the perception that FMD-3ABC ELISA alone or followed by liquid phase blocking ELISA is a useful technique for reliable detection of FMDV antibodies. However, it is noteworthy that lack of laboratory infrastructures in certain seaports or other border areas with high risk of FMD may be a limiting factor for using this assay as a routine diagnostic tool. In addition illegal animal movements which are always a threat to susceptible herds especially in border areas must be prohibited.

\section{Acknowledgements}

Authors are thankful to Mr. Mohamed Mostafa Shaheen, General Director of the Animal and Plant Quarantine of Jeddah Islamic seaport, Ministry of Agriculture, Jeddah, KSA for his cooperation and encouragement.

\section{References}

1. Astudillo, V., Rosenberg, F.J., Zottele, A. and Casasalascoaga, R. (1990): Consideracoes sobre a saude animal na America latina, Hora Vet. 9(54):37-43.

2. Bachrach, H.L. (1968): foot-and-mouth disease. Annu. Rev. Microbiol. 22, 201-244.

3. Blanco.E., Luis, J., Romero, Medhi, H. and jose-Manuel S.V. (2002): Serological evidence of FMD subclinical infection in sheep population during the 1999 epidemic in Morocco. Vet. Microbiol. 85(1): 13-21.

4. Brocchi, E., DeDiego, M.I., Berlinzani, A., Gamba, D. and DeSimone, F. (1998): Diagnostic potential of Mab based ELISAs for antibodies to non0structural proteins of FMDV to differentiate infection from vaccination. Proceeding of concerted action CT93-0909. Vet. Q.20:20-24.

5. Bronosvoort B.M.C., Sorensen K.J., Anderson, J., Corteyn A., Tanya V.N., Kitching R.P. and Morgan, K.L. (2004) : A comparison of two 2ABC ELISAs in a cattle population with endemic, multiple serotype foot-and-mouth disease. $J$. clinic. Microbiol. 42(5): 2108-2114.

6. Bruderer, U., swam, H., Haas, B., Visser, N., Brocchi, E. Grazioli, S., esterhuysen, J.J., Vosloow, F.M., Aggarwal, N., Cox, S., Armstrong, R. and Anderson, J. (2004): Differentiating infection from vaccination in foot-andmouth -disease: evaluation of an ELISA based on recombinant 3ABC. J. Vet. Microbiol. 14; 101(3): 187-97.

7. Clavijo, A., Wright, P., and Kitching (2004): Developments in diagnostic techniques for differentiating infection from vaccination in foot-and-mouth disease. Vet. J. 167 (1): 3-4.

8. Correa, M.E., Saraiva,V. and Astudillo, V. (2002) : Review of the status of Foot and mouth disease in countries of South America and approaches to control and eradication. Rev. Sci. Tech. Off. Int. Epiz. 2(3): 429-436.

9. DeDiego, M., Brocchi, E., Makay, D., and DeSimone, F. (1997) : The non-structural polyprotein 3ABC of FMDV as adiagnostic antigen in ELISA to differentiate infected from vaccinated cattle. Arch. Virol. 142, 2021-2033.

10. Dekker, A. and Gijsen, E. (1998): The possible use of native FMD non-structural protein $3 \mathrm{~A}$ in a serological screening test.Vet.Q.20:Suppl.2.

11. FAO, (2006): report of the $72^{\text {nd }}$ executive committee of the European Commission for the control of FMD.

12. Gilbert,M., Aktas, S., Mohammed, H., Roeder, P., Sumption, K., Tufan, M. and Sligenbergh, J. (2005) : patterns of spread and persistence of Foot-and-mouth disease types A,O and Asia-1 in Turkey ;a meta-population approach. Epidemiol. infec. 133(3): 537-545.

13. Gloster, J., et.al.(2007): Foot-and-mouth Quantification and size distribution of airborne particles emitted by healthy and infected pigs. Vet.J.174 (1): 42-53.

14. Hamblin, C., Barnett,I.T.R. and Hedger, R.S. (1986a): 
A new enzyme-linked immunosorbent assay (ELISA) for the detection of antibodies against foot and mouth disease virus. 1. Development and method of ELISA. J. Immunol. Methods. 93,115-121.

15. Hamblin, C., Barnett,I.T.R. and Crowther, J.R. (1986b): A new enzyme-linked immunosorbent assay (ELISA) for the detection of antibodies against foot and mouth disease virus.II.Applic. J. Immunol. Methods. 93,123-129.

16. Huang, C.C., Jong, M.H. and Lin, S.Y. (2000) Characterestics of foot and mouth disease virus in Taiwan. $J$. Vet. Med. Sci. 62(7): 677-679.

17. Kitching, R.P. and Hughes, G.J. (2002): Clinical variation of FMD: sheep and goats. Rev. Sci. Tech. Off. Int. Epiz., 21 (3): 505-512.

18. Lu, Z., Zhang, X., fu, Y., Tian, M., Sun, P., Li, D., Liu, Z. and Xie, Q. (2010) : Expression of the major epitope regions of $2 \mathrm{C}$ integrated with the $3 \mathrm{AB}$ non-structural protein of footand-mouth disease virus and its potential for differentiating infected from vaccinated animals. J. virol. Methods.170 (12): $128-33$

19. Mackay, D.K.J., Forsyth, M.A, Davis, P.R., Belsham, G.J., Flint, M. and Rayon, M.D. (1998): differentiating infection from vaccination in FMD using a panel of recombinant nonstructural proteins in ELISA. Vaccine. 16:446-459.

20. Mikkelsen, T., Alexandersen, S., Astrup, P.,Champion, H.J., Donaldson, A.I., Dunkerley,F.N., Gloster,J., Sorensen, J.H and Thykier-Nielsen, S. (2003) : Investigation of airborne Foot-and-mouth disease virus transmission during low-wind conditions in the early phase of the UK 2001 epidemic
Atmos. Chem. Phys. 3,2101-2110.

21. Malirat, V., Neitzert, E., Bergmann, I.E., Marade, E. and Beck, E. (1998) : Detection of cattle exposed to FMDv by means of an indirect ELISA test using bioengineered nonstructural polyprotein 3ABC. Vet.Q.20(2): 524-526.

22. OIE (World organization for Animal health), (2006):. World animal health situation, Viewed 21 April, 2006.

23. Pereira, H.G. (1981): Foot-and-mouth disease, In: Gibbs, E.P.G. (Ed.) virus diseases of foot animals, vol.2.Academic press Inc., New York, and PP.333-363.

24. Perry, B.D., Kalpravidth, W., Cleman, P.G., Horst, H.S. McDermott, J.J., Randolph, T.F. and Gleeson, L.J., (1999): The economic impact of Foot and mouth disease and its control in South-East Asia: a preliminary assessment with special refrence to Thailand. Rev. Sci. Tech. Off. Int. Epiz. 18(2): 478-497.

25. Potzsch, C.J., Brocchi, E., Grazioli, S., Greiner, M. Rozstalnyy, A., Staubach, C., Sumption, K. (2006) : Estimating the impact of Foot-aand-mouth disease vaccination in buffer zones in the southern Caucasus The role of sero-surveillance."Proceedings of the $11^{\text {th }}$ international symposium on veterinary epidemiology and economics, 2006.

26. Rayan.J.,(2000): FMD Situation in Europe and other regions in 1999/2000 .The European commission for the control of Foot and Mouth disease. Reports archive: 64 session appendix 1.

27. Sorensen, K.J., brocchi, E., Mackay, D., and DeSimone, F. (1997): FMD. Detection of antibodies in cattle sera by blocking ELISA. Vet. Microbiol. 23(3-4): 253-265. 